\title{
Ponencia en las II Jornadas del Departamento de Psicoanálisis "Analistas hablando de su práctica»
}

\section{Luis Giunipero}

En esta oportunidad los quiero invitar a compartir reflexiones sobre cuatro frases, de las cuales tres están extraídas del Seminario "Los cuatro conceptos fundamentales del psicoanálisis" de Lacan. (Lacan, 1964)

La primera de ellas refiere a que "el analista forma parte del concepto de inconsciente". ${ }^{1}$ (Lacan, 1964:131) Sobre todo me dirigido a los más jóvenes pues los que han transitado cierto recorrido clínico ya se han decidido a formar parte del concepto de inconsciente. Desde luego, recién lo charlaba con algunos chicos y la verdad es que ellos tienen derecho a elegir, entre las diversas propuestas que tiene hoy un psicólogo en cómo abordar la clínica. Para ellos, entonces, cito esta frasecita muy consistente y condensadora de desarrollos: "el analista forma parte del concepto de inconsciente" (Lacan, 1964:131)

La segunda frase - que pueden buscarla en el capítulo "La presencia del analista" del Seminario mencionado- sitúa que "la transferencia es la manera de tratar al paciente y la manera de tratarlo define el concepto". ${ }^{2}$ (Lacan, 1964:130) Ya veremos sus incidencias.

La tercera frase contiene una definición fuerte ya que ubica que "la transferencia es la puesta en acto de la realidad del inconsciente." (Lacan, 1964:155)

Por último, la cuarta frase - que pertenece a un querido amigo y colega analista que es Carlos Kuri- me permite transmitirles cómo la práctica freudiana construye la teoría y la práctica del análisis. En su texto Kuri plantea que el problema de la clínica del análisis apura a la metapsicología. Fíjense que son cinco palabras pero tienen una rigurosidad enorme. "La clínica apura a la metapsicología."

Entonces supongamos que queremos empezar por el lado de la clínica para reflexionar sobre estas proposiciones: "La clínica apura a la metapsicología"; "La transferencia es puesta en acto de la realidad del inconsciente"; "El analista forma parte del concepto de inconsciente" y "El modo de tratar a los pacientes determina el concepto." 
Les cuento momentos de la práctica clínica como analista. Un paciente ya en análisis, es decir en el dispositivo del análisis, al asociar libremente le retorna lo que se llama decir sin retener. La letra aludida era de un tango que decía "era más blanda que el agua, que el agua blanda”. Él se detiene y se queda pensando de quién es ese tango y despliega, entonces, un eje metonímico relacionado a autores de tango hasta que aparece Espósito.

Espósito queda en el lugar de una pregunta, en tanto, lo deriva a la cuestión de su propia filiación. Los niños expósitos son los que no tienen padres. Entonces hago una pequeña formula que es, si Espósito es el significante que, en ese momento, lo representa como sujeto para otros significantes en un goce tienen ustedes acá lo que se escribe como la fórmula del fantasma. Al igual que mis colegas que han hablado acá, se trata de que si el analista forma parte del concepto de inconsciente escucha el significante. Y sobre eso creo que los tres hemos de insistir enormemente. En sus intervenciones, Miguel Ferrero acentuó mucho en el no comprender y Juan Ritvo en el deseo del analista.

En este sentido, si el analista forma parte del concepto de inconsciente es porque el mismo opera, es decir, el inconsciente parlotea y habla hasta por los codos. Si el analista no forma parte del inconsciente, como ocurre habitualmente, queda del lado de la resistencia y no hace existir al concepto. El inconsciente -dice Freud- sería el socio ideal del capitalista porque cuando duerme trabaja generando sueños, cuando se divierte produce chistes y cuando alguien entra en situaciones ligadas a la angustia produce síntomas. Esta es la famosa triada de la clínica freudiana: inhibición síntoma y angustia. La angustia, especialmente, es una afecto muy ordenador en nuestra práctica porque orienta a nivel estructural. Más aun, la vamos a encontrar en cualquier estructura y en las diversas formas en que se singularice. Me refiero a las neurosis obsesivas, las fobias o la clínica de las psicosis.

Si volvemos al decir de este paciente, la aparición de Espósito lo lleva hacia una situación que lo interroga porque nunca puede filiarse y sentir que tiene un lugar para sostener una práctica. Su vida es errática y ligada al campo del arte pero en ningún lugar se puede filiar. Entonces creo que en ese sentido, el análisis le hace escuchar algo que retorna de su propia historia y que tiene que ver con la cura. Esto significa que cuando uno escucha significantes que lo determinan tiene la posibilidad de correrse de ese lugar, es decir, de estar advertido. Al menos advertido, que no es poco.

Les cuento otro pequeño relato. Viene un muchacho de 35 años derivado por la pediatra de su hijo que, además de estar especializada en el Hospital Garrahan, es una mujer que sabe mucho. Le pide que venga a hablar conmigo porque su chiquito 
de cuatro años no salta y apenas camina. Obviamente al hablar el padre de este hijo sobre ese miedo de saltar, es decir, miedo al juego donde se implica el cuerpo, aparece en el transcurrir del relato su mujer que tomó el comando -no lo voy a hacer largo. Ella se dedica a las letras, por lo cual, lee y escribe mucho y, desde luego, el chiquito con cuatro años sorprende a todos por su inteligencia y su capacidad de leer. De tal modo, está todo el tiempo jugando con la computadora y adónde va se hace un lugar a partir de mostrar estas cuestiones de modo superlativo. Entonces, el chiquitito tiene una gran llegada al mundo de las niñas quienes lo alojan como un genio, es decir, como un hijo que despierta admiración.

Empezamos a trabajar la cuestión y él me dice -por eso tengamos presente que los pequeños fragmentos son fundamentales- que se está dando cuenta que viene acá para que lo ayude a que, en tanto padre, él pueda dar algunos chirlitos. Ese es el significante que está en la transferencia que lo representa como sujeto para otros. Efectivamente, si el no puede hacerlo su hijo va a quedar pegado a la madre y también a su historia porque el abuelo materno es escritor, también muy ligado a la literatura. Como verán aquí hay una operatoria paterna que sino ordena a través de poner límites el niño enferma. Por eso, en este caso, el significante es chirlitos.

Ahora imagínense, sobre todo los más jóvenes -porque los más experimentados lo recontra conocen- que estas situaciones plantean el valor de la eficacia del análisis. El caso es que estábamos con el tema del chirlito -para los más jóvenes sobre todoporque ustedes saben lo importante que es que tu papá empiece a pensar que, a partir de la falta de los chirlitos, algunas operatorias paternas no están operando. En otras palabras, es la salud psíquica de ese niño la que está en juego porque si ellas faltan puede desarrollar una neurosis importante.

De este modo, la actualidad nos propone que la eficacia de un análisis opera si el analista forma parte del concepto de inconsciente, si su manejo de la transferencia no hace resistencia a la puesta en acto de la realidad del inconsciente y si el analista se soporta en su práctica tomando la clínica pero revisando, permanentemente, sus fundamentos que sería lo que plantea Carlos a partir de la metapsicología. Es decir, que el fundamento de lo que hago -es lo que hizo Freud todo el tiempo- está en el ida y vuelta entre la clínica y la metapsicología. Ahora imagínense la eficacia que tiene porque, ya con algunas entrevistas, tanto al niño como al padre les va cambiando la vida. No lo hago largo porque no tiene sentido. Quiero transmitir esta intervención del analista que no es sobre comprender, explicar o identificar su saber sino que está en relación a una escucha significante que produce los efectos que un análisis procura. Y los efectos son altamente beneficiosos. 
Tal cual lo planteó Miguel, en otras estrategias clínicas lo que se produce es la articulación de la transferencia a la sugestión. Y esta última deriva a la identificación al otro como ideal, o sea, al amor. Pero eso tiene patas cortas y por eso no es permanente. En cambio, nosotros trabajamos la transferencia como puesta en acto articulada a la repetición. Y la repetición del significante orienta la intervención del analista hacia la interpretación. Por eso insistía mucho en el valor para el analista de que su práctica se fundamente en lo metapsicológico, a partir de la frase precisa de Kuri.

Por otra parte, es posible encontrarnos también con personas en quienes ya empieza a operar lo que Lacan llamó la iniciativa del Otro. Me refiero a pacientes que estarían del lado de lo que llamamos clínica de las psicosis -ya sea que se están desencadenando o ya están desencadenadas- donde el Otro con mayúscula ya tomó la iniciativa. Nosotros le podemos poner muchos nombres, psicosis ordinarias y otros. Para mi sinceramente es irrelevante. Prefiero la posición de Freud que es la pregunta ¿podemos hacer algo con eso? y la clínica precisa que la psicosis tiene una lógica y, fundamentalmente, porque contamos con cómo Lacan lo ha sistematizado de manera ejemplar. Entonces nosotros también podemos estar frente a esa clínica y ofertar algo que tiene una gran utilidad. Habitualmente vamos a trabajar con psicosis medicadas o que van a necesitar de medicación. Me refiero a las psicosis clínicas conocidas como esquizofrenia, paranoia, melancolía y manía.

Con respecto a la paranoia, creo que es un modo de resolver el desencadenamiento y plantear una estabilización. La pregunta en transferencia es si con eso que retorna como forcluido -porque al psicótico le falta el significante primordial- el paciente conseguirá arreglárselas frente a las demandas de la vida. Por figurarlo de algún modo, aparece una mujer, es decir, su deseo por ella pero él lo vive como una cuestión de vida o muerte. El otro día un joven, que sabe que hay una mujer que le gusta, me decía: "pero para mí es como ponerme un..." claro, uno está advertido. Yo sé que por ahí no tenemos que ir. Porque es empujarlo al pasaje al acto. Frente a la inmersión de angustia que le produce la mujer si uno lo empuja con ideales neuróticos de curación lo precipita sin posibilidad de retorno.

Ahora, ¿cómo se sabe esto? Se sabe porque está la metapsicología, es decir, lo que fundamenta las intervenciones. Se sabe que si un analista opera mal en transferencia con un psicótico tiene como consecuencia el pasaje al acto. Entonces, no se trata de que uno se asuste y no intervenga sino de intervenir fundamentado.

De esta manera, en ese movimiento de interrogar si la transferencia lo permite uno puede -no desde el saber sino desde la pregunta- tratar de situar si eso que retorna como forcluido tiene que ver con la historia del sujeto, en tanto a él le interese trabajar 
en esa dirección. Efectivamente son muchos los pacientes -independientemente de su estructura- a los que les interesa estar en análisis y escuchar su historia, escuchar cómo eso retorna y, a veces, se produce un aflojamiento de la certeza delirante que es el modo en como retorna ese saber, es decir, un cierto despegarse del dominio de los perseguidores. Sino no se podría hacer nada.

Realmente creo que aún en esta clínica y con ese modo de retorno, si la transferencia que se logra con el paciente contiene la pregunta, se puede trabajar y muy bien para aliviarlo. Porque en esta estructura -yo dije antes que la angustia es estructural- el psicótico se angustia más que el neurótico porque tiene menos defensa. Los neuróticos tenemos los fantasmas más o menos organizados incluso, rígidamente organizados y, por lo tanto, somos tan poco creativos. Entonces frente a la angustia se tiene más respuesta porque en el otro se encuentra con algo que le falta, es decir, con el agujero, y debido a ello como el agujero no lo persigue tiene más posibilidad de creación. Entonces dependerá de cada uno de ellos.

Nosotros tenemos la enorme transmisión que fueron Schreber y Joyce, sin embargo ninguno de los dos tuvieron analista sino que se trataron solos, si es cierto que Joyce era psicótico. Entonces lo que tenemos son pacientes que han desencadenado y, en función de ello, tratamos de instalar una transferencia donde el modo de situar el lugar del analista sea formando parte del inconsciente. De este modo, los significantes que traen contarán con la posibilidad de ser escuchados. Porque si no el psicótico ¿cómo se arregla con la angustia? Cuando el delirio no alcanza va al pasaje al acto. O, por el contrario, a un empobrecimiento de la vida al modo del ermitaño, tal cual lo señala Lacan. Un ermitaño es alguien que se sale del mundo de las demandas y queda estabilizado ahí.

Insisto, nuevamente, que hay que tener mucho cuidado en no llevar la dirección de la cura desde ideales neuróticos de progreso como que sean independientes o esas historias. Pero sí poder situar alguna alternativa que no sea la estabilización sino la posibilidad de construir lo que llamamos suplencia.

Lo conseguido por el dispositivo asistencial está muy bien porque es importante que un paciente muy perseguido y excitado consiga una estabilización. Nosotros en ese dispositivo- porque muchos de ustedes forman parte como acompañantes o tratantes terapéuticos- tenemos la posibilidad de ofertar una transferencia donde eso pueda ser también interrogado no desde el saber sino, en tanto, el paciente logre tolerar una pregunta.

En principio hasta acá.

(Aplausos) 
Notas Ampliatorias

1. "la propia presencia del analista es una manifestación del inconsciente (...)" (Lacan, 1964: 131).

2. “(...) la transferencia. Este concepto está determinado por la función que tiene en una praxis. Este concepto rige la manera de tratar a los pacientes.

A la inversa, la manera de tratarlos rige al concepto." (Lacan, 1964: 130).

3. "la transferencia es la puesta en acto de la realidad del inconsciente." (Lacan, 1964: 155)

4. "La clínica apura a la metapsicología.” (Kuri, 2011)

BibLIOGRAFÍA

Kuri, Carlos (2011). Vigencia de lo metapsicológico, en Cuadernos de Metapsicología 1, Rosario: Editora UNR, Volumen 1.

LaCan, JacQues (1963-1964). Los cuatro conceptos fundamentales. Lacan. El Seminario, Buenos Aires: Paidós (1993), Volumen 11. 